\title{
Prenatal diesel exhaust exposure disrupts the DNA methylation profile in the brain of mouse offspring
}

\author{
Ken Tachibanaa1,2, Kohei Takayanagi', Ayame Akimoto', Kouji Ueda', Yusuke Shinkai', \\ Masakazu Umezawa1,2 and Ken Takeda ${ }^{1,2}$ \\ ${ }^{1}$ Department of Hygienic Chemistry, Faculty of Pharmaceutical Sciences, Tokyo University of Science, \\ 2641 Yamazaki, Noda, Chiba 278-8510, Japan \\ ${ }_{2}^{2}$ The Center for Environmental Health Science for the Next Generation, Research Institute for Science and \\ Technology, Tokyo University of Science, 2641 Yamazaki, Noda, Chiba 278-8510, Japan
}

(Received September 8, 2014; Accepted November 4, 2014)

\begin{abstract}
Prenatal diesel exhaust (DE) exposure is associated with detrimental health effects in offspring. Although previous reports suggest that DE exposure affects the brain of offspring in the developmental period, the molecular events associated with the health effects have largely remained unclear. We hypothesized that the DNA methylation state would be disrupted by prenatal DE exposure. In the present study, the authors examined the genome-wide DNA methylation state of the gene promoter and bioinformatically analyzed the obtained data to identify the molecular events related to disrupted DNA methylation. Pregnant C57BL/6J mice were exposed to DE (DEP; $0.1 \mathrm{mg} / \mathrm{m}^{3}$ ) in an inhalation chamber on gestational days $0-16$. Brains were collected from 1-day-old and 21-day-old offspring. The genomewide DNA methylation state of the brain genome was analyzed by methylation-specific DNA immunoprecipitation and subsequent promoter tiling array analysis. The genes in which the DNA methylation level was affected by prenatal DE exposure were bioinformatically categorized using Gene Ontology (GO). Differentially methylated DNA regions were detected in all chromosomes in brains collected from both 1-day-old and 21-day-old offspring. Altered DNA methylation was observed independently of the presence of $\mathrm{CpG}$ island. Bioinformatic interpretation using GO terms showed that differentially methylated genes with $\mathrm{CpG}$ islands in their promoter were commonly enriched in neuronal differentiation and neurogenesis. The results suggest that prenatal DE exposure causes genome-wide disruption of DNA methylation in the brain. Disrupted DNA methylation would disturb neuronal development in the developmental period and may be associated with health and disease in later life.
\end{abstract}

Key words: Brain, DNA methylation, Diesel exhaust, Prenatal exposure

\section{INTRODUCTION}

Epidemiological and experimental studies have shown that exposure to fine ambient particulate matter (PM) is related to respiratory and cardiovascular disorders (Pope et al., 2004; Liu et al., 2008; Ostro et al., 2006). Diesel exhaust (DE) is one of the main types of air pollution and is a major source of fine ambient PM in urban environments (Donaldson et al., 2005). For this reason, DE exposure models have been used to investigate the health effects of ambient PM. Several studies have indicated that DE exposure may affect the central nervous system. For instance, railroad workers exposed to DE have shown neurobehavioral impairment (Kilburn,
2000), and human volunteers exposed to DE have shown altered electrical signals in the frontal cortex (Crüts et al., 2008). Previously, we reported that prenatal DE exposure affects the brain of offspring with regard to neurotransmitter levels and spontaneous locomotor activity (Suzuki et al., 2010). Other studies have shown that prenatal DE exposure induces neuroinflammation and affects behavior in mouse offspring (Bolton et al., 2012; Thirtamara Rajamani et al., 2013). Peters et al. (2013) indicated that prenatal DE exposure increases the risk of childhood brain tumors. Although these reports suggest that DE exposure affects the brain of offspring in the developmental period, the molecular event involved in these health effects has largely remained unclear.

Correspondence: Ken Tachibana (E-mail: tachibana@nichiyaku.ac.jp) 
DNA methylation is a critical mechanism of epigenetic gene regulation (Deaton and Bird, 2011). In mammals, methylation almost exclusively occurs on the cytosine residue of $\mathrm{CpG}$ dinucleotide. $\mathrm{CpG}$ islands are GC-rich DNA regions that possess relatively high densities of $\mathrm{CpG}$ dinucleotide. They are found in many genes, positioned mainly at the 5' ends. Their methylation state is closely associated with gene transcription activity. DNA methylation results in transcriptional silencing, either by interfering with a transcription factor binding or by inducing heterochromatin structure. DNA methyltransferases, DNMT1, DNMT3a and DNMT3b, are responsible for the methylation of cytosine residue in $\mathrm{CpG}$ sites (Bergman and Cedar, 2013). DNMT3a and DNMT3b play crucial roles in de novo cytosine methylation, while DNMT1 works by maintaining the DNA methylation pattern in the newly synthesized DNA during cell division. Knockout studies of DNA methyltransferases have shown that DNA methylation is essential for complete embryonic development (Li et al., 1992; Okano et al., 1999).

In the developmental period, the DNA methylation pattern derived from germ cells disappears when the fertilized egg develops into a blastocyst. The de novo methylation pattern is then reestablished at around the stage of implantation (Kafri et al., 1992). The global DNA methylation level also changes in the early postnatal stages (Tawa et al., 1990). This dynamic regulation of the DNA methylation state during the developmental period would provide a mechanism for the removal of errors in gene methylation patterns derived from germ lines; thus allowing normal development. These DNA methylation processes during development are associated with long-lasting phenotypic changes, including genomic imprinting, cell differentiation, and X-chromosome inactivation (Roth et al., 2009). Previous studies indicated that dysregulation of DNA methylation contributes to neuronal disorders such as Rett syndrome, fragile X mental retardation and immunodeficiency, centromeric region instability, and facial anomalies syndrome (ICF) (Amir et al., 1999; Sutcliffe et al., 1992; Tucker, 2001). These phenomena led the authors to suspect that prenatal DE exposure disrupts the DNA methylation pattern and subsequently induces neuronal defects in the brain of offspring.

In the present study, we analyzed the effect of prenatal DE exposure on the DNA methylation state in the brain of offspring mice. The methylation state of the promoter DNA region throughout the entire genome was analyzed with a combination of methylated DNA immunoprecipitation (MeDIP) and promoter tilling array analysis. The differentially methylated genes were then categorized bioinformatically using Gene Ontology (GO) to identify the molecular events associated with altered DNA methylation induced by prenatal DE exposure. Furthermore, Medical Subject Headings (MeSH) analysis was used to identify the brain regions preferentially affected by DE exposure.

\section{MATERIALS AND METHODS}

\section{Animals and exposure}

C57BL/6J mice were purchased from SLC (Shizuoka, Japan) and housed under controlled conditions (temperature: $22 \pm 1{ }^{\circ} \mathrm{C}$, humidity: $50 \pm 5 \%$ ) with a $12 \mathrm{hr}$ light $/ 12 \mathrm{hr}$ dark cycle and ad libitum access to food and water. Pregnant mice were exposed to DE in an inhalation chamber for $8 \mathrm{hr}$ per day (10:00-18:00) from gestational day 0-16 (DE exposed-group). Pregnant mice of the control group were housed in a clean air chamber. After delivery, offspring were housed in clean air. All experiments were handled in accordance with the institutional and national guidelines for the care and use of laboratory animals.

\section{Diesel exhaust}

A four-cylinder 2,179 cc diesel engine (Isuzu Motors, Tokyo, Japan) was operated at a speed of 1,500 rpm and $80 \%$ load with diesel fuel. The exhaust was introduced into a stainless steel dilution tunnel (216.3 mm diameter $\times 5250 \mathrm{~mm})$ where the exhaust was mixed with clean air. The mass and number concentrations of DEP were measured by a Piezobalance Dust Monitor (model 3521, Kanomax Japan, Osaka, Japan) and a condensation particle counter (model 3007, TSI Inc., Shoreview, MN, USA), respectively. Concentrations of gas components, (nitric oxide $\left[\mathrm{NO}_{\mathrm{X}}\right], \mathrm{SO}_{2}$, and $\mathrm{CO}$ ) in the chambers were measured by a NO-NO$-\mathrm{NO}_{\mathrm{X}}$ analyzer (model $42 \mathrm{i}$; Thermo Fisher Scientific, Franklin, MA, USA), an Enhanced Trace Level $\mathrm{SO}_{2}$ Analyzer (model 43i-TLE; Thermo Fisher Scientific), and a CO Analyzer (model 48i; Thermo Fisher Scientific), respectively.

\section{DNA extraction}

Brain tissues were removed from $1 \mathrm{~d}$ and $21 \mathrm{~d}$ offspring of each dam (1d: 6 dams/group, 21d: 5 dams/group). The whole brain tissues obtained were homogenized in extraction buffer (10 mM Tris- $\mathrm{HCl}$ [pH8.0], 0.1 M EDTA, $0.5 \%$ SDS, $0.3 \mathrm{mg} / \mathrm{mL}$ Proteinase $\mathrm{K}$ ) and incubated at $55^{\circ} \mathrm{C}$ overnight. After RNase A treatment, genomic DNA was extracted by phenol/chloroform extraction, followed by ethanol precipitation. Extracted DNA of 1 male and 1 female from each dam was pooled for use in DNA methylation analysis. PCR amplification of genomic sequence of sex determining region (Sry) gene, which 
Prenatal diesel exhaust exposure disrupts the DNA methylation profile

is located on the Y chromosome, was performed to discriminate the sex of offspring.

\section{Methylated DNA immunoprecipitation (MeDIP)}

MeDIP was performed as previously described (Weber et al., 2005), with slight modifications. Before MeDIP assay, genomic DNA was sonicated to produce a random fragment, which mainly ranged from $500-1,000 \mathrm{bp}$. The fragmented DNA was denatured for $10 \mathrm{~min}$ at $95^{\circ} \mathrm{C}$ and subsequently incubated with anti-5-methyl cytosine antibody (Diagenode Inc., NJ, USA) in immunoprecipitation (IP) buffer (20 mM Tris- $\mathrm{HCl}$ [pH 8.0], $150 \mathrm{mM} \mathrm{NaCl}$, 2 mM EDTA, $1 \%$ Triton X-100) overnight at $4{ }^{\circ} \mathrm{C}$. Then, the mixture was incubated with Dynabeads M-280 Sheep anti-mouse $\mathrm{IgG}$ for $2 \mathrm{hr}$ at $4^{\circ} \mathrm{C}$. After washing with IP buffer, the beads were incubated with elution buffer (25 mM Tris-HCl [pH8.0], $10 \mathrm{mM}$ EDTA, 0.5\% SDS, $0.25 \mathrm{mM}$ DTT) for $15 \mathrm{~min}$ at $65^{\circ} \mathrm{C}$. Eluted DNA was recovered by phenol-chloroform extraction followed by ethanol precipitation.

\section{In vitro transcription}

T7 based amplification of methylated DNA obtained by MeDIP assay was performed as previously described (Liu et al., 2003), with slight modifications. DNA samples were treated with 5 units of Antarctic phosphatase (New England BioLabs, Ipswich, MA, USA). Poly T tails were generated using terminal transferase (New England BioLabs) with $100 \mu \mathrm{M}$ dTTP and $10 \mu \mathrm{M}$ ddCTP. The reaction was cleaned up with a MinElute Reaction Cleanup kit (Qiagen, Valencia, CA, USA) according to manufacturer's instructions. The tailing reaction product was mixed with T7-polyA primer (5'- GCATTAGCGGCCGCGAA ATTAATACGACTCACTATAGGGAG(A) ${ }_{18}$ C-3') in the reaction buffer (10 mM Tris- $\mathrm{HCl}[\mathrm{pH} 7.9], 50 \mathrm{mM} \mathrm{NaCl}$, $10 \mathrm{mM} \mathrm{MgCl}$, $1 \mathrm{mM}$ DTT, $0.2 \mathrm{mM}$ dNTP mix) and incubated at $95^{\circ} \mathrm{C}$ for $2 \mathrm{~min}$ to denature. After incubation, the reaction was held at $37^{\circ} \mathrm{C}$ for 2 min to anneal, ramped down to $25^{\circ} \mathrm{C}$ and held while Klenow enzyme (New England BioLabs) was added. The sample was then incubated at $37^{\circ} \mathrm{C}$ for $90 \mathrm{~min}$ for extension. The reaction was terminated by adding $0.5 \mathrm{M}$ EDTA ( $\mathrm{pH} 8.0$ ), then cleaned up with MinElute Reaction Cleanup kit (Qiagen). After the samples were condensed with a centrifugal vacuum evaporator, in vitro transcription was performed using a Megascript T7 kit (Ambion, Foster, CA, USA) according to manufacturer's instructions, with the exception that the incubation was increased to $16 \mathrm{hr}$. The resultant samples were purified with NucleoSpin RNA Clean-up kit (Machery-Nagel, Düren, Germany).

\section{Biotin-labeled double-stranded cDNA synthesis and promoter tiling array analysis}

To obtain double-stranded cDNA, amplified RNA was reverse transcribed, nick-translated and subsequently biotin-labeled with GeneChip WT Double-Stranded DNA Terminal Labeling Kit (Affymetrix, Santa Clara, CA, USA) according to manufacturer's instructions. Labeled double-stranded cDNA was used for promoter array analysis.

GeneChip mouse promoter 1.0R array (Affymetrix) was hybridized with biotin-labeled double-stranded cDNA using a GeneChip Hybridization, Wash and Stain kit (Affymetrix). The array was then scanned by Affymetrix GeneChip Command Console software. Labeling, hybridization and scanning were performed by Bio Matrix Research, Inc. (Chiba, Japan) using the standard protocol. Tiling Analysis Software (TAS, Affymetrix), was used to calculate signal intensities, normalize the signals, and generate p-values. The threshold setting for the analysis was set at $\mathrm{p}<0.01$. The detected DNA regions were annotated to genes using the probe information provided by Affymetrix. To analyze whether these genes have $\mathrm{CpG}$ islands, the genomic location of $\mathrm{CpG}$ islands in the entire mouse genome was obtained from the UCSC genome browser (Center for Biomolecular Science and Engineering, Santa Cruz, CA, USA).

\section{Bioinformatic analysis of methylated genes with GO and MeSH}

Differentially methylated genes were categorized with $\mathrm{GO}$ and $\mathrm{MeSH}$ terms. All promoter DNA regions analyzed by promoter tiling array were annotated with GO using an annotation file (ftp://ftp.ncbi.nih.gov/gene/DATA/ gene 2 go.gz) provided by the NCBI. All of the genes were annotated to MeSH terms using the Gene2MeSH programmatic interface provided by National Center for Integrative Biomedical Informatics (Ann Arbor, MI, USA). The annotations were updated in October 2013. The genes in which the DNA methylation level was affected by prenatal DE exposure were categorized using $\mathrm{GO}$ terms. Gene promoters with $\mathrm{CpG}$ islands were analyzed because the presence of a $\mathrm{CpG}$ island is crucial for transcriptional regulation. The enrichment factor for each category was defined as $(n f / n) /(N f / N)$, where $n f$ is the number of differentially methylated genes within the category; $N f$ is the total number of genes within that same category; $n$ is the number of differentially methylated genes within the entire tiling array; and $N$ is the total number of genes on the tiling array. Statistical analysis was performed using Fisher's exact test based on a hypergeometric distribution. Then the GO categories with enrichment 
factors $\geq 2, n f>5$ and $\mathrm{p}<0.05$ were extracted.

\section{RESULTS}

\section{Diesel exhaust characteristics}

The average number and mass concentration of the diesel exhaust particles (DEP) were approximately $7.1 \times 10^{4}$ number $/ \mathrm{cm}^{3}$ and $0.1 \mathrm{mg} / \mathrm{m}^{3}$, respectively. The average concentration of exhaust gases was maintained at $1.84 \mathrm{ppm}$ for carbon monoxide (CO), $0.456 \mathrm{ppm}$ for nitrogen monoxide (NO), $0.247 \mathrm{ppm}$ for nitrogen dioxide $\left(\mathrm{NO}_{2}\right)$, and $3.52 \mathrm{ppb}$ for sulfur dioxide $\left(\mathrm{SO}_{2}\right)$ (Table 1).

\section{Genome-wide analysis of the promoter DNA methylation state}

Probes on the promoter tiling array were annotated to 14,246 genes. The methylated promoter DNA regions specific to the control group and the DE-exposed group were defined as follows. The regions specific to the control group were those in which DNA methylation lev$\mathrm{el}$ in the DE-exposed group was decreased in comparison to the control group. The regions specific to the DE-exposed group were those in which DNA methylation level in the DE-exposed group was increased in comparison to the control group. These methylated promoter DNA regions were detected in all chromosomes (Figs. 1, 2; Supplementary Tables 1-4). We detected 3197, 3010, 3340 and 2820 genes with differentially methylated DNA regions in their promoter in 1-day-old (1d) male, 1d female, $21 \mathrm{~d}$ male and $21 \mathrm{~d}$ female offspring, respectively (Figs. 1, 2). Among these genes, 1689, 1905, 1760 and 1522 genes, respectively, have $\mathrm{CpG}$ islands (Fig. 1). These results showed that the differential methylation of the gene promoters occurred independently of the presence of $\mathrm{CpG}$ islands. Furthermore, altered DNA methylation was detected in both the $1 \mathrm{~d}$ and $21 \mathrm{~d}$ offspring. These results indicated that prenatal DE exposure disrupted the genome-wide DNA methylation state in the brain of offspring mice throughout the 1-21-day postpartum period.

\section{Categorization of differentially methylated genes with GO and MeSH}

Of the genes mapped to the promoters that were differentially methylated in the DE-exposed and control groups, 57, 74, 98 and $52 \mathrm{GO}$ categories were enriched in $1 \mathrm{~d}$ male, $1 \mathrm{~d}$ female, $21 \mathrm{~d}$ male and $21 \mathrm{~d}$ female offspring, respectively (Supplementary Tables 5-8). To obtain information about the biological function affected by altered DNA methylation in each time point, GO terms that were common between male and female offspring were extracted (Tables 2, 3). The GO terms related to neuronal differentiation ("positive regulation of neuron differentiation") and neurogenesis ("positive regulation of neurogenesis" and "neurogenesis") were found in both $1 \mathrm{~d}$ and $21 \mathrm{~d}$ offspring, respectively.

We also attempted to find the brain regions that were susceptible to prenatal DE exposure from the MeSH results. Although some MeSH terms indicate the brain regions that were enriched in each experimental group, we were not able to find MeSH terms common to each experimental point (Supplementary Tables 9-12).

\section{DISCUSSION}

Human epidemiologic and animal studies indicate that nutrition and environmental stimuli during prenatal and postnatal mammalian development influence developmental pathways and thereby induce permanent changes in metabolism and chronic disease susceptibility (McMillen and Robinson, 2005). Epigenetic mechanisms are likely to play an important role in this "developmental origins of health and diseases (DOHaD)" hypothesis (Waterland and Michels, 2007). DNA methylation is one of the pivotal mechanisms for the epigenetic regulation of gene transcription. The disruption of the DNA methylation pattern by prenatal chemical exposure is suspected to affect the development of offspring because the correct construction of this pattern is crucial for normal development. Several reports have suggested a relationship between developmental defects and the disruption of DNA methylation. Vinclozolin, an endocrine disruptor, which has antiandrogenic activity, transgenerationally alters the DNA methylation pattern in the male germ line (Anway et al., 2005). It has been indicated that the alteration of DNA methylation induced by maternal ethanol consumption is capable of inducing changes in gene

Table 1. Characteristics of diesel exhaust exposure.

\begin{tabular}{lccccccc}
\hline & $\mathrm{CO}(\mathrm{ppm})$ & $\mathrm{SO}_{2}(\mathrm{ppb})$ & $\mathrm{NO}(\mathrm{ppm})$ & $\mathrm{NO}_{2}(\mathrm{ppm})$ & $\mathrm{NO}_{\mathrm{x}}(\mathrm{ppm})$ & $\mathrm{DEP}\left(\mu \mathrm{g} / \mathrm{m}^{3}\right)$ & $\mathrm{DEP}\left(\mathrm{number} / \mathrm{cm}^{3}\right)$ \\
\hline Control air & $0.504 \pm 0.159$ & $1.22 \pm 0.83$ & $0.003 \pm 0.003$ & $0.019 \pm 0.008$ & $0.022 \pm 0.010$ & $5 \pm 4$ & $4 \pm 2$ \\
$\mathrm{DE}$ & $1.84 \pm 0.42$ & $3.52 \pm 1.20$ & $0.456 \pm 0.136$ & $0.247 \pm 0.070$ & $0.703 \pm 0.203$ & $98 \pm 29$ & $70920 \pm 24247$ \\
\hline
\end{tabular}

Values are the average concentration of each component in diesel exhaust and control air expressed as mean \pm S.D. 
Prenatal diesel exhaust exposure disrupts the DNA methylation profile

A

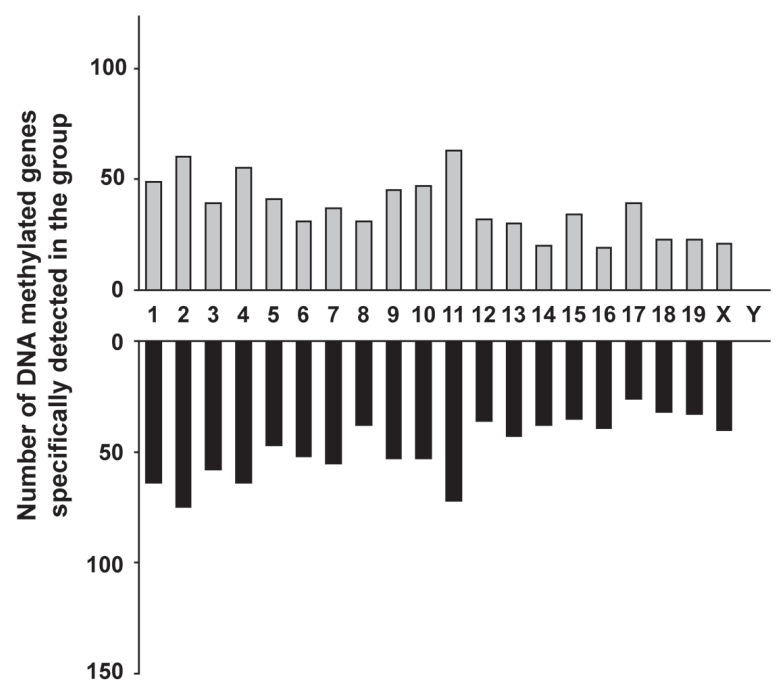

C

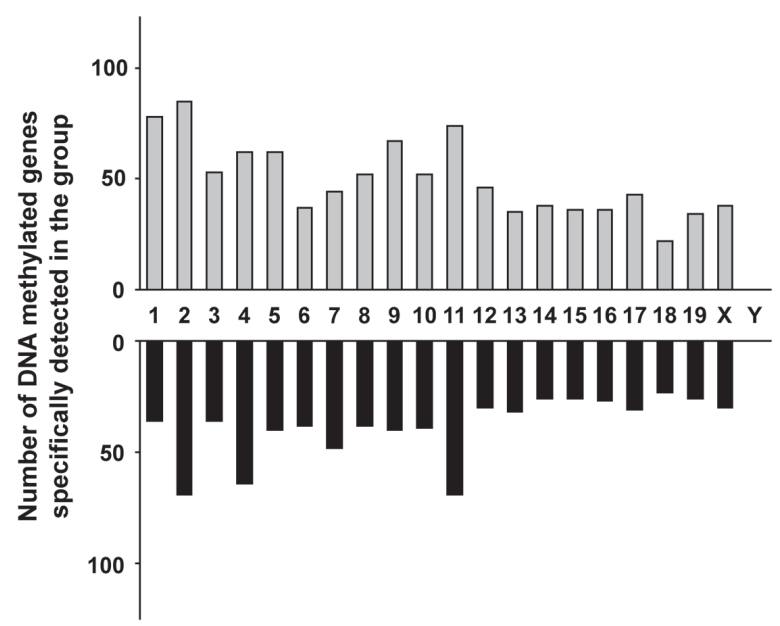

B

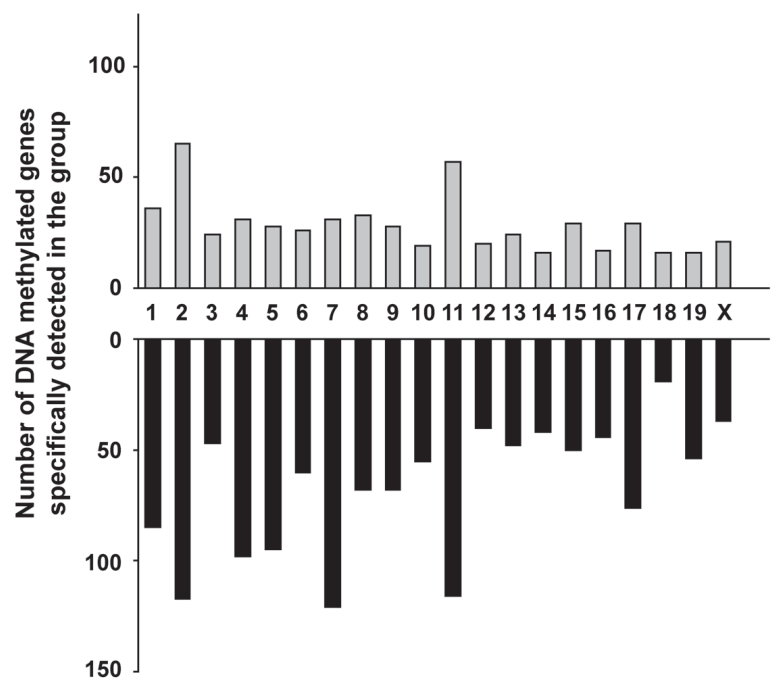

D

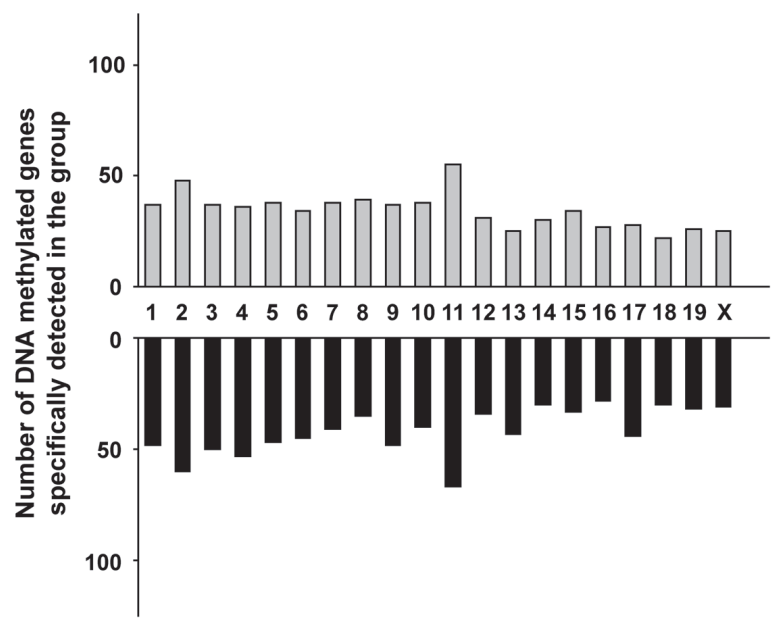

Fig. 1. Effects of prenatal diesel exhaust (DE) exposure on the DNA methylation state of gene promoters with CpG islands. The number of DNA methylated genes specifically detected in control and DE groups in 1-day-old (1d) male (A), 1d female (B), $21 \mathrm{~d}$ male (C) and 21d female (D) offspring. The $\mathrm{x}$-axis shows chromosome numbers. Black bars indicate the genes specifically methylated in control (meaning that DNA methylation was decreased by DE exposure). Gray bars indicate the genes specifically methylated in DE (meaning that DNA methylation was increased by DE exposure).

expression (Kaminen-Ahola et al., 2010). At the time of writing, however, it remains unclear whether prenatal DE exposure affects the genome-wide DNA methylation pattern in the brain of offspring.

We produced a mass concentration of DEP at about
$100 \mu \mathrm{g} / \mathrm{m}^{3}$, which is environmentally relevant. Previous report suggested that the effects of suspended PM in air pollutants are mainly derived from DEP (Donaldson et al., 2005). Numerous megacities in the world demonstrate PM concentrations of $30-600 \mu \mathrm{g} / \mathrm{m}^{3}$ in annual averag- 
K. Tachibana et al.

A

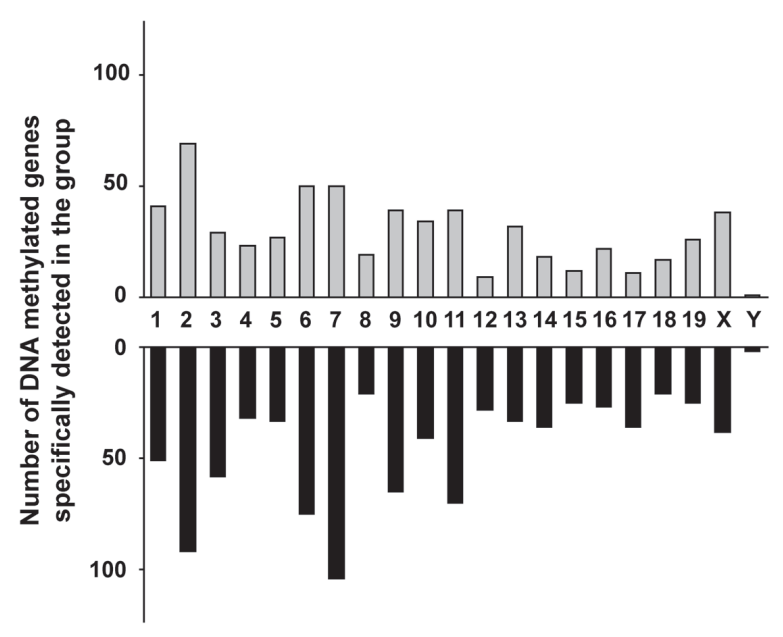

C

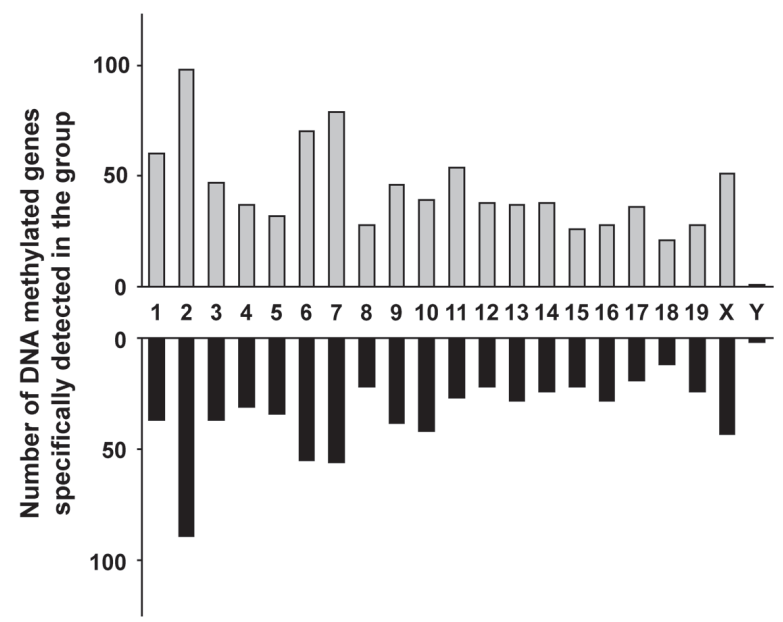

B

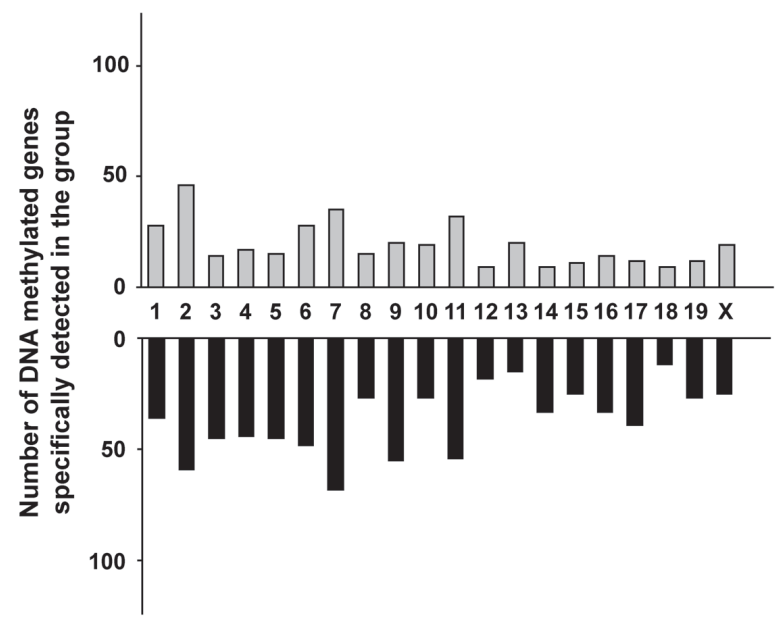

D

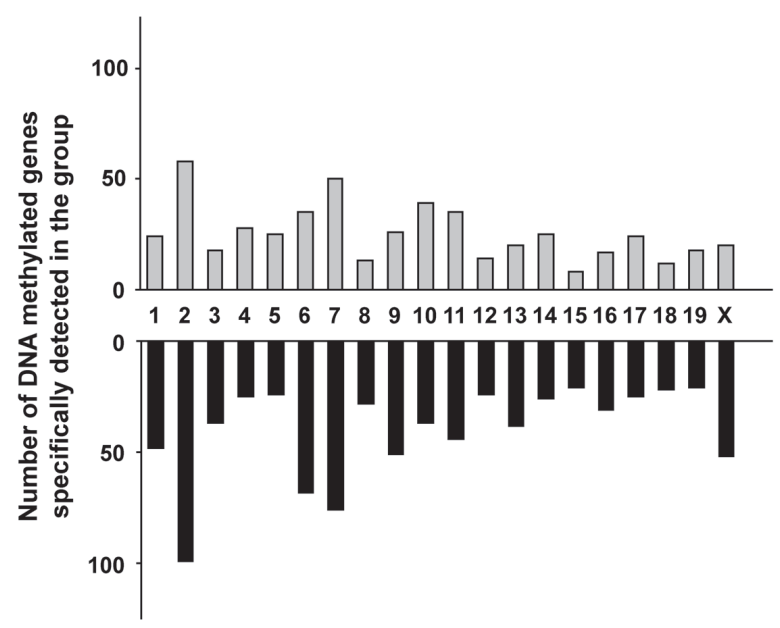

Fig. 2. Effects of prenatal diesel exhaust (DE) exposure on the DNA methylation state of gene promoters without CpG islands. The number of genes DNA methylated which were specifically detected in control and DE groups in 1-day-old (1d) male (A), $1 \mathrm{~d}$ female (B), 21d male (C) and 21d female (D) offspring. The x-axis shows chromosome numbers. Black bars indicate the genes specifically methylated in control (meaning that DNA methylation was decreased by DE exposure). Gray bars indicate the genes specifically methylated in DE (meaning that DNA methylation was increased by DE exposure).

es (Gurjar et al., 2008). For example, under the condition in the Mexico City $\left(201 \mu \mathrm{g} / \mathrm{m}^{3}\right)$ and assuming a ventilation rate of $6.4 \mathrm{~L} / \mathrm{min}\left(9.2 \mathrm{~m}^{3} /\right.$ day $)$ for a healthy adult at rest (Crosfill and Widdicombe, 1961), the total amount of PM exposure would be approximately $1,800 \mu \mathrm{g} / \mathrm{m}^{3}$. This would correspond to $6 \mu \mathrm{g} /$ day of PM exposure for a mouse with an average ventilation rate of $0.021 \mathrm{~L} / \mathrm{min}$
(Crosfill and Widdicombe, 1961). The DE exposure under the condition of present study was approximately $1 \mu \mathrm{g}$ /day. In the present study, the DE exposure condition for DEP mass concentration and exposure time was designed to be lower than recent studies on the effects of DE exposure on the central nervous system (Levesque et al., 2011a, 2011b; Win-Shwe et al., 2012; Yamagishi et 
Prenatal diesel exhaust exposure disrupts the DNA methylation profile

Table 2. GO terms commonly enriched in male (M) and female (F) in 1-day-old offspring.

\begin{tabular}{lccc}
\hline GO term & Gender & Enrichment factor & p-value \\
\hline Positive regulation of neuron differentiation & $\mathrm{M}$ & 2.01 & 0.007 \\
& $\mathrm{~F}$ & 2.23 & $<0.001$ \\
Ventricular septum morphogenesis & $\mathrm{M}$ & 4.20 & $<0.001$ \\
& $\mathrm{~F}$ & 3.39 & $<0.001$ \\
Outflow tract morphogenesis & $\mathrm{M}$ & 2.80 & 0.001 \\
& $\mathrm{~F}$ & 2.69 & $<0.001$ \\
RNA polymerase II core promoter proximal region sequence-specific DNA binding & $\mathrm{M}$ & 2.17 & 0.025 \\
& $\mathrm{~F}$ & 2.80 & $<0.001$ \\
Embryonic cranial skeleton morphogenesis & $\mathrm{M}$ & 2.56 & 0.015 \\
Histone deacetylase binding & $\mathrm{F}$ & 2.92 & 0.002 \\
& $\mathrm{M}$ & 2.10 & 0.008 \\
Cardiac muscle cell differentiation & $\mathrm{F}$ & 2.01 & 0.004 \\
tRNA binding & $\mathrm{M}$ & 2.19 & 0.048 \\
\end{tabular}

The enrichment factor for each category was defined as described in MATERIALS AND METHODS. Statistical analysis was performed using Fisher's exact test with hypergeometric distribution and the level of statistical significance was set at $p<0.05$

Table 3. GO terms commonly enriched in male (M) and female (F) in 21-day-old offspring.

\begin{tabular}{lccc}
\hline GO categories & Gender & Enrichment factor & p-value \\
\hline Neurogenesis (positive regulation of neurogenesis) & $\mathrm{M}$ & 2.83 & 0.008 \\
& $\mathrm{~F}$ & 2.54 & 0.025 \\
Hindbrain development & $\mathrm{M}$ & 2.85 & 0.013 \\
mRNA transport & $\mathrm{F}$ & 4.93 & $<0.001$ \\
& $\mathrm{M}$ & 2.06 & 0.012 \\
Dorsal/ventral pattern formation & $\mathrm{F}$ & 2.77 & 0.001 \\
& $\mathrm{M}$ & 2.08 & 0.033 \\
Spermatid development & $\mathrm{F}$ & 2.66 & 0.003 \\
& $\mathrm{M}$ & 2.20 & 0.009 \\
Centriole & $\mathrm{F}$ & 2.33 & 0.006 \\
& $\mathrm{M}$ & 2.51 & 0.001 \\
Transcription cofactor activity & $\mathrm{F}$ & 2.28 & 0.007 \\
Epithelial to mesenchymal transition & $\mathrm{M}$ & 2.69 & 0.006 \\
& $\mathrm{~F}$ & 2.72 & 0.011 \\
Odontogenesis of dentin-containing tooth & $\mathrm{M}$ & 2.69 & 0.011 \\
Protein targeting & $\mathrm{F}$ & 2.66 & 0.020 \\
\end{tabular}

The enrichment factor for each category was defined as described in MATERIALS AND METHODS. Statistical analysis was performed using Fisher's exact test with hypergeometric distribution and the level of statistical significance was set at $p<0.05$.

al., 2012).

In the present study, we used the combination of MeDIP and subsequent promoter tilling array analysis to examine the effects of prenatal DE exposure on the genome-wide promoter DNA methylation state in the brain of offspring mice. Our results revealed that prenatal DE exposure disrupted the DNA methylation state of offspring in all chromosomes rather than a particular 
chromosome. Furthermore, altered DNA methylation was observed in both $1 \mathrm{~d}$ and $21 \mathrm{~d}$ offspring. To understand the molecular events influenced by DE exposure, differentially methylated genes were bioinformatically categorized using GO terms. This bioinformatic interpretation indicated that differentially DNA methylated genes were enriched in the GO terms related to neuronal differentiation and neurogenesis. These results suggest that aberrant DNA methylation induced by prenatal DE exposure affects neuronal development. The fetal and neonatal period is critical for the development and organization of the neuronal network (Sporns et al., 2004; Smyser et al., 2010). We previously reported that prenatal DE exposure affects spontaneous locomotor activity and monoaminergic system in mice (Suzuki et al., 2010). The genes which aberrant DNA methylation was observed in this study would be associated with development and organization of the monoaminergic system in mice. The detailed analysis about this point is required to clarify the association between aberrant DNA methylation and functional changes in mice.

The regulation of gene expression during fetal and neonatal period is associated with morphological and functional development of the brain (Muotri and Gage, 2006). Given that the established DNA methylation pattern is generally maintained through cell division (Bergman and Cedar, 2013), it is predicted that altered DNA methylation would be partially maintained after development. Several reports suggest a relationship between aberrant DNA methylation and neurodegenerative diseases such as Alzheimer's, Huntington's, and Parkinson's disease (Jakovcevski and Akbarian, 2012). In addition, cortical neuron degeneration has also been observed in canines that inhaled air pollutants containing PM (CalderónGarcidueñas et al., 2002). When the information from these reports is considered, it would seem that altered DNA methylation induced by prenatal DE exposure would also be associated with the later pathogenesis of neurodegenerative disorder. In the present study, we observed that the genes which showed altered DNA methylation were different between $1 \mathrm{~d}$ and $21 \mathrm{~d}$ offspring. These results suggested that the aberrant DNA methylation pattern induced by prenatal DE exposure was partially recovered during growth. Further examinations about DNA methylation in young adult mice are required to clarify the DNA region which shows persistent aberrant DNA methylation.

The authors detected the altered DNA methylation of the genes independently of the presence of $\mathrm{CpG}$ islands. Several reports indicate a relationship between reactive oxygen species (ROS) and DNA methylation. Oxi- dative DNA damage is known to disturb the binding of methyltransferase to the DNA (Valinluck et al., 2004), thus resulting in hypomethylation of cytosine residue. Weitzman et al. (1994), showed that DNA methylation can be influenced by free radical adducts on adjacent guanine residues. Taken together, it seems possible that ROS associated with DE inhalation (Li et al., 2010) could disrupt the DNA methylation state in the developing tissues. Since DNA hypomethylation induces genomic instability (Chen et al., 1998), a decrease in genome-wide DNA methylation may lead to an increase in the mutation rate that is induced by prenatal DEP exposure (Ritz et al., 2011).

We previously reported a bioinformatic method for locating candidate brain regions of interest for the effects of nanoparticle exposure using MeSH terms (Umezawa et al., 2012). We applied the method to survey the brain regions that are preferentially affected by prenatal DE exposure. Although several MeSH terms related to brain region were enriched in each experimental group, no common regions were found in the comparisons. With regard to the effects of DE exposure, it therefore seems less likely that any brain region is a specific target for DNA methylation disruption.

In the present study, we interpreted the biological effects caused by differential gene methylation using a bioinformatic method. Further "wet experiments" are required to clarify whether disrupted DNA methylation actually alters the gene expression, neural differentiation, and the function of central nervous systems especially monoaminergic systems which are affected by prenatal DE exposure (Suzuki et al., 2010). Additionally, the molecular mechanisms underlying the effect of prenatal DE exposure on the DNA methylation pattern remain unknown. As indicated above, the disturbance of DNA methyltransferase binding (Valinluck et al., 2004) is potentially involved in the dysregulation of DNA methylation. In addition, the biological systems that determine the DNA regions that are methylated are another possible target of DE exposure. Previous reports indicated some factors essential for the establishment and maintenance of the methylation imprint, including Zfp57 and PGC7/Stella (Li et al., 2008; Nakamura et al., 2007). Shen et al. (2013), showed that a dynamic methylationdemethylation cycle occurs at a large number of genomic loci. These molecules and pathways would also be candidate targets of prenatal DE exposure. Recently, a portion of the piRNA, small RNA exclusively expressed in the germ line, was linked to de novo DNA methylation (Olovnikov et al., 2012). Wick et al. (2010) showed that particles up to a diameter of $240 \mathrm{~nm}$ were taken up by 
Prenatal diesel exhaust exposure disrupts the DNA methylation profile

the placenta and, further, were able to cross the placental barrier. The findings in this report suggest that a part of DEP, especially nano-sized particles (diameter $<100 \mathrm{~nm}$ ), might be transferred to fetus. On the other hand, Weaver et al. (2005) showed maternal stress alters the epigenotype in rodent offspring. The analysis about whether DEP or maternal stress disrupts the molecules/pathways which indicated above would help to solve the problem.

Our results showed that altered DNA methylation pattern was different between male and female offspring. Previous reports suggest that steroid hormone and endocrine disruptor change DNA methylation (Jost and Saluz, 1993; Anway et al., 2005; Skinner et al., 2010). Watanabe and Kurita (2001) showed the possibility that prenatal DE exposure alters fetal testosterone levels. Brain sex differences organized by a transient hormone surge may be maintained through epigenetic modification (McCarthy et al., 2009). Our results, combined with these reports, showed the possibility that prenatal DE exposure affects the brain sex difference through alteration of DNA methylation in the developmental stage.

In conclusion, the present study showed that prenatal DE exposure disrupts the genome-wide DNA methylation state in the brain of offspring mice. Bioinformatic GO analysis showed that differentially DNA methylated genes were enriched in neuronal differentiation. These results suggest that disrupted DNA methylation in the infertile mouse brain is involved in neural dysfunctions induced by prenatal DE exposure. Bioinformatic interpretation of the altered DNA methylation data using GO terms may provide clues that lead to the better understanding of the molecular events underlying the effects of prenatal DE exposure in the developmental period. In addition, a decrease in genome-wide DNA methylation may lead to increased mutation rate, which is induced by prenatal DEP exposure. Our results suggest that the earlylife social environments in which DE is present could be critical for the construction of the DNA methylation pattern and may be associated with a long-term impact on health.

\section{ACKNOWLEDGEMENTS}

We thank the graduate and undergraduate students at the Takeda laboratory for their help with the experiments. We also thank Dr. Masaya Ohtsu (Tokyo University of Science) for helpful discussion. This work was supported in part by a JSPS KAKENHI Grant, Number 22710067 (Ken Tachibana); a MEXT-Supported Program for the Strategic Research Foundation at Private Universities, 2011-2015 (Ken Takeda); and a Grant-in-Aid for the
Health and Labour Science Research Grant, Research on the Risk of Chemical Substances, from the Ministry of Health, Labour and Welfare of Japan (Ken Takeda).

Conflict of interest---- The authors declare that there is no conflict of interest.

\section{REFERENCES}

Amir, R.E., Van den Veyver, I.B., Wan, M., Tran, C.Q., Francke, U. and Zoghbi, H.Y. (1999): Rett syndrome is caused by mutations in X-linked MECP2, encoding methyl-CpG-binding protein 2. Nat. Genet., 23, 185-188.

Anway, M.D., Cupp, A.S., Uzumcu, M. and Skinner, M.K. (2005): Epigenetic transgenerational actions of endocrine disruptors and male fertility. Science, 308, 1466-1469.

Bergman, Y. and Cedar, H. (2013): DNA methylation dynamics in health and disease. Nat. Struct. Mol. Biol., 20, 274-281.

Bolton, J.L., Smith, S.H., Huff, N.C., Gilmour, M.I., Foster, W.M., Auten, R.L. and Bilbo, S.D. (2012): Prenatal air pollution exposure induces neuroinflammation and predisposes offspring to weight gain in adulthood in a sex-specific manner. FASEB J., 26, 4743-4754.

Calderón-Garcidueñas, L., Azzarelli, B., Acuna, H., Garcia, R., Gambling, T.M., Osnaya, N., Monroy, S., DEL Tizapantzi, M.R., Carson, J.L., Villarreal-Calderon, A. and Rewcastle, B. (2002): Air pollution and brain damage. Toxicol. Pathol., 30, 373-389.

Chen, R.Z., Pettersson, U., Beard, C., Jackson-Grusby, L. and Jaenisch, R. (1998): DNA hypomethylation leads to elevated mutation rates. Nature, 395, 89-93.

Crosfill, M.L. and Widdicombe, J.G. (1961): Physical characteristics of the chest and lungs and the work of breathing in different mammalian species. J. Physiol., 158, 1-14.

Crüts, B., van Etten, L., Törnqvist, H., Blomberg, A., Sandström, T., Mills, N.L. and Borm, P.J. (2008): Exposure to diesel exhaust induces changes in EEG in human volunteers. Part. Fibre Toxicol., 5, 4.

Deaton, A.M. and Bird, A. (2011): CpG islands and the regulation of transcription. Genes Dev., 25, 1010-1022.

Donaldson, K., Tran, L., Jimenez, L.A., Duffin, R., Newby, D.E., Mills, N., MacNee, W. and Stone, V. (2005): Combustion-derived nanoparticles: a review of their toxicology following inhalation exposure. Part. Fibre Toxicol., 2, 10.

Gurjar, B.R., Butler, T.M., Lawrence, M.G. and Lelieveld, J. (2008): Evaluation of emissions and air quality in megacities. Atmospheric Environment, 42, 1593-1606.

Jakovcevski, M. and Akbarian, S. (2012): Epigenetic mechanisms in neurological disease. Nat. Med., 18, 1194-1204.

Jost, J.P. and Saluz, H.P. (1993): Steroid hormone dependent changes in DNA methylation and its significance for the activation or silencing of specific genes. EXS, 64, 425-451.

Kafri, T., Ariel, M., Brandeis, M., Shemer, R., Urven, L., McCarrey, J., Cedar, H. and Razin, A. (1992): Developmental pattern of gene-specific DNA methylation in the mouse embryo and germ line. Genes Dev., 6, 705-714.

Kaminen-Ahola, N., Ahola, A., Maga, M., Mallitt, K.A., Fahey, P., Cox, T.C., Whitelaw, E. and Chong, S. (2010): Maternal ethanol consumption alters the epigenotype and the phenotype of offspring in a mouse model. PLoS Genet., 6, e1000811.

Kilburn, K.H. (2000): Effects of diesel exhaust on neurobehavioral 
and pulmonary functions. Arch. Environ. Health, 55, 11-17.

Levesque, S., Surace, M.J., McDonald, J. and Block, M.L. (2011a): Air pollution \& the brain: Subchronic diesel exhaust exposure causes neuroinflammation and elevates early markers of neurodegenerative disease. J. Neuroinflammation, 8, 105.

Levesque, S., Taetzsch, T., Lull, M.E., Kodavanti, U., Stadler, K., Wagner, A., Johnson, J.A., Duke, L., Kodavanti, P., Surace, M.J. and Block, M.L. (2011b): Diesel exhaust activates and primes microglia: air pollution, neuroinflammation, and regulation of dopaminergic neurotoxicity. Environ. Health Perspect., 119, 1149-1155.

Li, E., Bestor, T.H. and Jaenisch, R. (1992): Targeted mutation of the DNA methyltransferase gene results in embryonic lethality. Cell, 69, 915-926.

Li, X., Ito, M., Zhou, F., Youngson, N., Zuo, X., Leder, P. and Ferguson-Smith, A.C. (2008): A maternal-zygotic effect gene, Zfp57, maintains both maternal and paternal imprints. Dev. Cell, 15, 547-557.

Li, Y.J., Takizawa, H. and Kawada, T. (2010): Role of oxidative stresses induced by diesel exhaust particles in airway inflammation, allergy and asthma: their potential as a target of chemoprevention. Inflamm. Allergy Drug Targets, 9, 300-305.

Liu, C.L., Schreiber, S.L. and Bernstein, B.E. (2003): Development and validation of a $\mathrm{T} 7$ based linear amplification for genomic DNA. BMC Genomics, 4, 19.

Liu, J., Ballaney, M., Al-alem, U., Quan, C., Jin, X., Perera, F., Chen, L.C. and Miller, R.L. (2008): Combined inhaled diesel exhaust particles and allergen exposure alter methylation of $\mathrm{T}$ helper genes and IgE production in vivo. Toxicol. Sci., 102, 76-81.

McCarthy, M.M., Auger, A.P., Bale, T.L., De Vries, G.J., Dunn, G.A., Forger, N.G., Murray, E.K., Nugent, B.M., Schwarz, J.M. and Wilson, M.E. (2009): The epigenetics of sex differences in the brain. J. Neurosci., 29, 12815-12823.

McMillen, I.C. and Robinson, J.S. (2005): Developmental origins of the metabolic syndrome: prediction, plasticity, and programming. Physiol. Rev., 85, 571-633.

Muotri, A.R. and Gage, F.H. (2006): Generation of neuronal variability and complexity. Nature, 441, 1087-1093.

Nakamura, T., Arai, Y., Umehara, H., Masuhara, M., Kimura, T., Taniguchi, H., Sekimoto, T., Ikawa, M., Yoneda, Y., Okabe, M., Tanaka, S., Shiota, K. and Nakano, T. (2007): PGC7/Stella protects against DNA demethylation in early embryogenesis. Nat. Cell. Biol., 9, 64-71.

Okano, M., Bell, D.W., Haber, D.A. and Li, E. (1999): DNA methyltransferases Dnmt3a and Dnmt3b are essential for de novo methylation and mammalian development. Cell, 99, 247-257.

Olovnikov, I., Aravin, A.A. and Fejes Toth, K. (2012): Small RNA in the nucleus: the RNA-chromatin ping-pong. Curr. Opin. Genet. Dev., 22, 164-171.

Ostro, B., Broadwin, R., Green, S., Feng, W.Y. and Lipsett, M. (2006): Fine particulate air pollution and mortality in nine California counties: results from CALFINE. Environ. Health Perspect., 114, 29-33.

Peters, S., Glass, D.C., Reid, A., de Klerk, N., Armstrong, B.K., Kellie, S., Ashton, L.J., Milne, E. and Fritschi, L. (2013): Parental occupational exposure to engine exhausts and childhood brain tumors. Int. J. Cancer, 132, 2975-2979.

Pope, C.A.3rd, Burnett, R.T., Thurston, G.D., Thun, M.J., Calle, E.E., Krewski, D. and Godleski, J.J. (2004): Cardiovascular mortality and long-term exposure to particulate air pollution: epidemiological evidence of general pathophysiological pathways of disease. Circulation, 109, 71-77.

Ritz, C., Ruminski, W., Hougaard, K.S., Wallin, H., Vogel, U. and Yauk, C.L. (2011): Germline mutation rates in mice following in utero exposure to diesel exhaust particles by maternal inhalation. Mutat. Res., 712, 55-58.

Roth, T.L., Lubin, F.D., Sodhi, M. and Kleinman, J.E. (2009): Epigenetic mechanisms in schizophrenia. Biochim. Biophys. Acta., 1790, 869-877.

Shen, L., Wu, H., Diep, D., Yamaguchi, S., D’Alessio, A.C., Fung, H.L., Zhang, K. and Zhang, Y. (2013): Genome-wide analysis reveals TET- and TDG-dependent 5-methylcytosine oxidation dynamics. Cell, 153, 692-706.

Skinner, M.K., Manikkam, M. and Guerrero-Bosagna, C. (2010): Epigenetic transgenerational actions of environmental factors in disease etiology. Trends Endocrinol. Metab., 21, 214-222.

Smyser, C.D., Inder, T.E., Shimony, J.S., Hill, J.E., Degnan, A.J., Snyder, A.Z. and Neil, J.J. (2010): Longitudinal analysis of neural network development in preterm infants. Cereb. Cortex., 20, 2852-2862.

Sporns, O., Chialvo, D.R., Kaiser, M. and Hilgetag, C.C. (2004): Organization, development and function of complex brain networks. Trends Cogn. Sci., 8, 418-425.

Sutcliffe, J.S., Nelson, D.L., Zhang, F., Pieretti, M., Caskey, C.T., Saxe, D. and Warren, S.T. (1992): DNA methylation represses FMR-1 transcription in fragile X syndrome. Hum. Mol. Genet., $1,397-400$.

Suzuki, T., Oshio, S., Iwata, M., Saburi, H., Odagiri, T., Udagawa, T., Sugawara, I., Umezawa, M. and Takeda, K. (2010): In utero exposure to a low concentration of diesel exhaust affects spontaneous locomotor activity and monoaminergic system in male mice. Part. Fibre Toxicol., 7, 7.

Tawa, R., Ono, T., Kurishita, A., Okada, S. and Hirose, S. (1990): Changes of DNA methylation level during pre- and postnatal periods in mice. Differentiation, 45, 44-48.

Thirtamara Rajamani, K., Doherty-Lyons, S., Bolden, C., Willis, D., Hoffman, C., Zelikoff, J., Chen, L.C. and Gu, H. (2013): Prenatal and early-life exposure to high-level diesel exhaust particles leads to increased locomotor activity and repetitive behaviors in mice. Autism. Res., 6, 248-257.

Tucker, K.L. (2001): Methylated cytosine and the brain: a new base for neuroscience. Neuron, 30, 649-652.

Umezawa, M., Tainaka, H., Kawashima, N., Shimizu, M. and Takeda, K. (2012): Effect of fetal exposure to titanium dioxide nanoparticle on brain development - brain region information. J. Toxicol. Sci., 37, 1247-1252.

Valinluck, V., Tsai, H.H., Rogstad, D.K., Burdzy, A., Bird, A. and Sowers, L.C. (2004): Oxidative damage to methyl-CpG sequences inhibits the binding of the methyl-CpG binding domain (MBD) of methyl-CpG binding protein 2 (MeCP2). Nucleic. Acids. Res., 32, 4100-4108.

Watanabe, N. and Kurita, M. (2001): The masculinization of the fetus during pregnancy due to inhalation of diesel exhaust. Environ. Health Perspect., 109, 111-119.

Waterland, R.A. and Michels, K.B. (2007): Epigenetic epidemiology of the developmental origins hypothesis. Annu. Rev. Nutr., 27, 363-388.

Weaver, I.C., Champagne, F.A., Brown, S.E., Dymov, S., Sharma, S., Meaney, M.J. and Szyf, M. (2005): Reversal of maternal programming of stress responses in adult offspring through methyl supplementation: altering epigenetic marking later in life. J. Neurosci., 25, 11045-11054.

Weber, M., Davies, J.J., Wittig, D., Oakeley, E.J., Haase, M., Lam, 
Prenatal diesel exhaust exposure disrupts the DNA methylation profile

W.L. and Schubeler, D. (2005): Chromosome-wide and promoter-specific analyses identify sites of differential DNA methylation in normal and transformed human cells. Nat. Genet., 37, 853-862.

Weitzman, S.A., Turk, P.W., Milkowski, D.H. and Kozlowski, K. (1994): Free radical adducts induce alterations in DNA cytosine methylation. Proc. Natl. Acad. Sci. USA, 91, 1261-1264.

Wick, P., Malek, A., Manser, P., Meili, D., Maeder-Althaus, X., Diener, L., Diener, P.A., Zisch, A., Krug, H.F. and von Mandach, U. (2010): Barrier capacity of human placenta for nanosized materials. Environ. Health Perspect., 118, 432-436.

Win-Shwe, T.T., Yamamoto, S., Fujitani, Y., Hirano, S. and Fujimaki, H. (2012): Nanoparticle-rich diesel exhaust affects hippocampal-dependent spatial learning and NMDA receptor subunit expression in female mice. Nanotoxicology, 6, 543-553. Yamagishi, N., Ito, Y., Ramdhan, D.H., Yanagiba, Y., Hayashi, Y., Wang, D., Li, C.M., Taneda, S., Suzuki, A.K., Taya, K., Watanabe, G., Kamijima, M. and Nakajima, T. (2012): Effect of nanoparticle-rich diesel exhaust on testicular and hippocampus steroidogenesis in male rats. Inhal. Toxicol., 24, 459-467. 